\title{
Iceberg Shape Affects Melting
}

\author{
Experiments with large ice cubes show that the melting rate depends on \\ the shape, an effect that climate modelers may need to consider.
}

\author{
By Mark Buchanan
}

si ceberg melting is an important component of global climate simulations, but current models ignore some features, including iceberg shapes. Combining experiments on blocks of ice with computer simulations, researchers have now demonstrated that an iceberg's shape can greatly affect its melting rate [1]. They found that narrower icebergs that extend deeper underwater melt faster than wider ones that are less deeply submerged. The researchers expect that this new understanding can help climate scientists improve models used to predict how ice melting will affect Earth's oceans and climate.

Melting ice sheets-including those in Greenland and Antarctica-add fresh water (with low salinity) to the oceans, with important consequences for the global climate. Roughly $45 \%$ of the melting comes from icebergs that have broken away from an ice sheet, so understanding iceberg melting is important for climate models. Icebergs come in an enormous range of shapes and sizes; the depths they reach also varies, though they rarely extend below $600 \mathrm{~m}$. Researchers classify

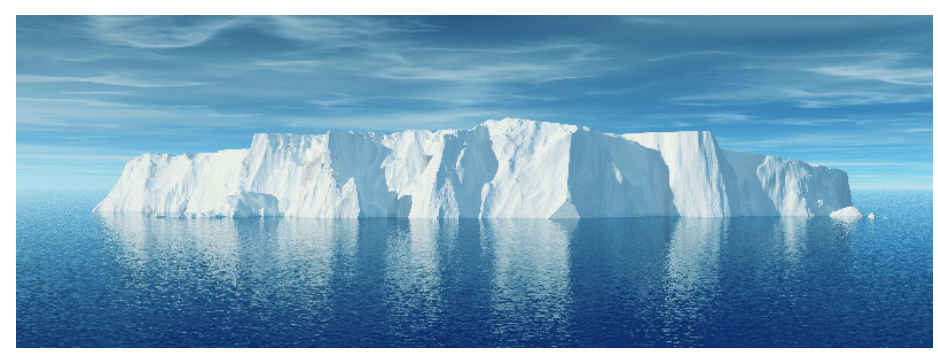

The cold facts. Melting icebergs add fresh water to the oceans, with potential consequences for the planet's climate. Experiments show that iceberg shape-tall and narrow versus short and wide-has a large effect on melting rate, which for some icebergs may be $50 \%$ faster than previously thought.

Credit: Orlando Florin Rosu/stock.adobe.com

icebergs by their aspect ratio-defined as the ratio of the longest horizontal dimension ("length") to the submerged depth-a parameter that can vary from 1 to 1000. (It's a common misconception that icebergs extend deep underwater compared with their length at the surface; in fact, buoyancy can cause them to roll to reduce their submerged volume.)

Researchers know that as an iceberg is carried by currents, melting rates differ among the front, rear, sides, and underside (called the base) as a result of temperature variations and differences in the fluid flow. So icebergs having different aspect ratios may melt at different rates. To measure the effects of iceberg shape, Eric Hester of the University of Sydney and colleagues carried out a series of experiments, checking their results against detailed computer simulations.

The researchers partially submerged rectangular blocks of ice that were between 10 and $33 \mathrm{~cm}$ in length, holding them stationary in a flow of salt water. For each experiment, the team allowed melting to occur for ten minutes and then weighed the block to determine the melted mass. They also used photos to find the melting rate for each face independently.

At the highest flow speeds of $3.5 \mathrm{~cm}$ per second, the researchers found, the different faces of the iceberg melted at different rates, with the fastest melting occurring at the front face. This was expected, says Hester, as previous experiments have shown that flows directed against a surface generate higher melting than flows parallel to a surface. But these experiments provided new details. For example, "iceberg sides melt roughly twice as fast as iceberg bases," Hester says, so the shape affects the total rate of melting. "Wide icebergs, being mostly base, should melt more slowly, and narrower icebergs, with more side area, should melt faster." Hester and colleagues also found that numerical simulations produced similar results. 


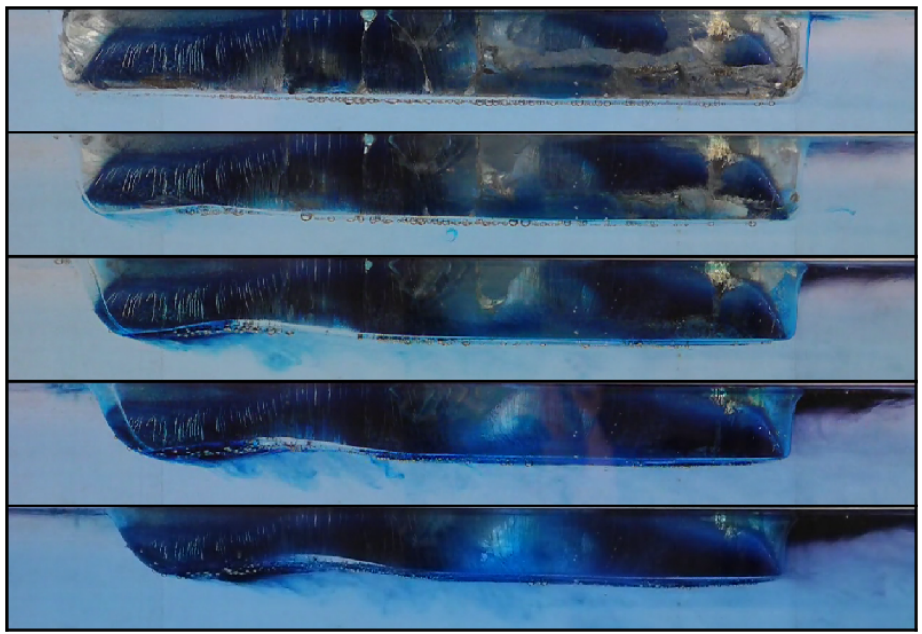

Imitation iceberg. The photos show an ice block after melting for $0,2,4,6$, and 8 minutes (top to bottom) when submerged to a depth of $3 \mathrm{~cm}$ in a salt water bath flowing from left to right. Blue dye in the ice aids visualization of the meltwater.

Credit: E. W. Hester et al. [1]

Given the wide range of iceberg aspect ratios, the experiments suggest that small icebergs may melt at a rate $50 \%$ faster than large ones, which can be several hundred kilometers long. But models commonly used for geophysical ice sheet modeling don't account for the effect of aspect ratio on melting rate, so Hester says the work could lead to improved models. In addition, the experiments predict higher melt rates than these models, a result that the models may also need to include.

"This study is unique in using both laboratory experiments and numerical simulations to look at the patterns of iceberg melt in a flow," says oceanographer Fiammetta Straneo of the Scripps Institute of Oceanography in San Diego. "We cannot make these kinds of measurements in the ocean." She says the information is needed to determine how long icebergs survive before melting, where their meltwater is released, and how it will affect ocean circulation.

Mark Buchanan is a freelance science writer who splits his time between Abergavenny, UK, and Notre Dame de Courson, France.

\section{REFERENCES}

1. E. W. Hester et al., "Aspect ratio affects iceberg melting," Phys. Rev. Fluids 6, 023802 (2021). 